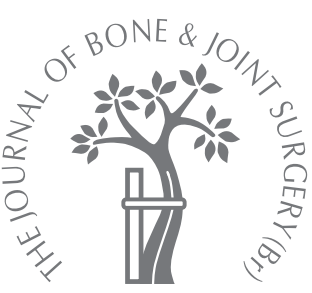

W. C. W. Chan, P. Musonda, A. S. Cooper, M. M. S. Glasgow, S. T. Donell, N. P. Walton

From Norfolk and Norwich University Hospital, Norwich, England

\title{
One-stage versus two-stage bilateral unicompartmental knee replacement
}

\author{
A COMPARISON OF IMMEDIATE POST-OPERATIVE \\ COMPLICATIONS
}

We retrospectively studied the major complications occurring after one- and two-stage bilateral unicompartmental knee replacements (UKR). Between 1999 and 2008, 911 patients underwent 1150 UKRs through a minimally invasive approach in our unit. Of these, 159 patients ( $318 \mathrm{UKRs}$ ) had one-stage and 80 patients (160 UKRs) had two-stage bilateral UKRs.

The bilateral UKR groups were comparable in age and American Society of Anaesthesiology grade, but more women were in the two-stage group $(p=0.019)$. Mechanical thromboprophylaxis was used in all cases. Major complications were recorded as death, pulmonary embolus, proximal deep-vein thrombosis and adverse cardiac events within $\mathbf{3 0}$ days of surgery. No statistical differences between the groups were found regarding the operating surgeon, the tourniquet time or minor complications except for distal deep-vein thrombosis. The anaesthetic times were longer for the two-stage group $(p=0.0001)$.

Major complications were seen in 13 patients $(8.2 \%)$ with one-stage operations but none were encountered in the two-stage group $(p=0.005)$. Distal deep-vein thrombosis was more frequent in the two-stage group $(p=0.036)$.

Because of the significantly higher risk of major complications associated with one-stage bilateral UKR we advocate caution before undertaking such a procedure.

W. W. W. Chan, MA, MBBChir, MRCS, Core Surgical Trainee 1 A. S. Cooper, RGN, ONC DipHE, Research Nurse M. M. S. Glasgow, FRCS(Orth), Consultant Orthopaedic Surgeon I. S. T. Donell, MD, FRCS(Orth), Consultant Orthopaedic Surgeon and Academic Reader N. P. Walton, FRCS(Orth), Consultant Orthopaedic Surgeon

Department of Orthopaedics Norwich and Norfolk University Hospital NHS Trust, Colney Lane, Norwich NR4 7UY, UK.

- P. Musonda, MSc, $\mathrm{PhD}$ (Medstats), Honorary Lecturer, Medical Statistician School of Medicine, Health Policy and Practice University of East Anglia, Chancellor's Drive, Norwich NR4 7TJ, UK.

Correspondence should be sent to Mr W. C. W. Chan; e-mail: warwickchan@cantab.net

(C)2009 British Editorial Society of Bone and Joint Surgery doi:10.1302/0301-620X.91B10. $22612 \$ 2.00$

$J$ Bone Joint Surg [Br] 2009;91-B:1305-9. Received 18 March 2009; Accepted after revision 18 May 2009
Bilateral knee replacement may be performed as a one- or a two-stage procedure. Some authors have noted more immediate post-operative complications with a one-stage procedure ${ }^{1-4}$ but others have not noted an increase. ${ }^{5-7}$ Proponents of the one-stage bilateral TKR believe that the benefits include a shorter hospital stay, shorter total anaesthetic time and greater convenience for the patient as well as economic advantages 8,9 compared to the two-stage TKR. ${ }^{10}$

The Oxford Unicompartmental Knee Replacement (UKR) (Biomet, Bridgend, United Kingdom) has been shown to have a $95 \%$ ten-year survival. ${ }^{11}$ With appropriate patient selection and correct surgical technique, ${ }^{12}$ it can provide reliable symptomatic relief and correction of leg alignment, with an improvement in the range of movement in patients with single compartment arthritis.

Compared to TKR, UKR may have a lower post-operative complication rate owing to the less invasive approach and shorter operative and anaesthetic times, ${ }^{13}$ a reduced length of hospital stay, and quicker overall rehabilitation. ${ }^{13,14}$ Studies on bilateral UKR have not been reported.
We have compared the early complication rates between patients with one-stage bilateral UKR and those who had a two-stage procedure.

\section{Patients and Methods}

Between August 1999 and August 2008, 911 patients (1150 knees) underwent UKR at our Hospital. A retrospective study of the database identified 159 patients (318 knees) who had undergone one-stage bilateral UKR and 80 patients (160 knees) with a two-stage bilateral UKR. A minimally invasive technique $^{15}$ and the Oxford UKR prosthesis were used in all cases.

In all, ten surgeons had operated on all 239 patients, with eight being involved with both groups and two in one group only. One surgeon in particular had a higher proportion of patients, especially in the one-stage compared to the two-stage group (Table I). Only nine patients (18 knees, 11\%) in the two-stage group had each procedure performed by a different surgeon.

Bilateral one-stage UKR included procedures which were either simultaneous with 
Table I. Surgeons involved in the study and distribution of single- and two-stage procedures

\begin{tabular}{|c|c|c|c|c|c|}
\hline \multirow[b]{2}{*}{ Surgeon } & \multicolumn{4}{|l|}{ Number of knees } & \multirow[b]{2}{*}{ Total proportion $(n=478)(\%)$} \\
\hline & One-stage (consecutive) & One-stage (simultaneous) & One-stage $(n=318)(\%)$ & Two-stage $(n=160)(\%)$ & \\
\hline$A$ & 174 & 8 & $182(57.2)$ & $53(33.1)$ & $235(49.1)$ \\
\hline C & 36 & 4 & $40(12.6)$ & $12(7.5)$ & $52(10.9)$ \\
\hline D & 10 & 0 & $10(3.1)$ & $24(15.0)$ & $34(7.1)$ \\
\hline$E$ & 20 & 0 & $20(6.3)$ & $7(4.4)$ & $27(5.6)$ \\
\hline G & 10 & 0 & $10(3.1)$ & $8(5.0)$ & $18(3.8)$ \\
\hline $\mathrm{H}$ & 6 & 0 & $6(1.9)$ & $4(2.5)$ & $10(2.1)$ \\
\hline I & 4 & 0 & $4(1.3)$ & $0(0.0)$ & $4(0.8)$ \\
\hline J & 0 & 0 & $0(0.0)$ & $4(2.5)$ & $4(0.8)$ \\
\hline
\end{tabular}

two surgical teams or conducted consecutively by one team. Of the 159 one-stage replacements, six patients (12 knees) were identified to be simultaneous. Two-stage bilateral UKRs were defined as procedures that were performed at least a month apart involving two anaesthetics and two hospital admissions, and carried out within the study period. These three groups were then assessed.

The mean interval between the staged procedures was 1.5 years (SD 0.8). The main determinant in pursuing a two-stage approach was the patient's choice. These patients elected to have the most symptomatic knee operated on first.

A total of 127 men and 112 women underwent bilateral UKR. The primary diagnosis was osteoarthritis in all patients. Data including age, gender, tourniquet and total anaesthetic time and comorbidities were collected from a review of the medical records. The American Society of Anaesthesiologists (ASA) grading system ${ }^{16}$ was used based on their pre-operative anaesthetic assessment. ${ }^{17-20}$ The length of in-patient hospitalisation was recorded as the day of admission to the day of discharge.

All procedures were conducted under a general anaesthetic with a local anaesthetic infiltration to the knee at the end of the operation. All involved the use of a tourniquet. The duration of anaesthesia was recorded in minutes for the one-stage and a sum for each operation for both procedures in the two-stage group. All patients were part of an accelerated discharge programme, which had as its target $80 \%$ discharged within 24 hours for unilateral UKR. Chemical venous thromboprophylaxis was not routinely given. Intra-operative mechanical calf pumps and early mobilisation was employed. All patients had the same postoperative protocol involving blood tests, imaging and physiotherapy, with the emphasis on early mobilisation. All patients were followed up at six weeks, and if no concerns were raised their further review was continued in a dedicated physiotherapy-led UKR follow-up clinic.

Complications occurring during the initial postoperative period of 30 days were recorded. We recorded the major complications traditionally associated with joint arthroplasty $^{4}$ as death, pulmonary embolism, proximal deep-vein thrombosis (DVT), myocardial infarction and cardiac arrhythmia. Minor complications included superficial wound infection and distal DVT. Patients with clinical symptoms suggestive of a DVT were also recorded.

Statistical analysis. Statistical tests and analyses were conducted using STATA/SE 10.1 (STATA Corporation, College Station, Texas). Continuous data which were not normally distributed such as age and time, were analysed using the Mann-Whitney U test. Dichotomous data were analysed using Fisher's exact test. Statistical significance was defined as a $\mathrm{p}$-value $\leq 0.05$.

\section{Results}

There were no differences between one- and two-stage UKR with respect to mean age, ASA grade and mean individual tourniquet times for both legs, but there was a significant difference in gender distribution between the two groups and in the total anaesthetic time (Table II). The overall age distribution between the two groups was also comparable (Fig. 1).

All 239 patients in the study were ASA grade I, II or III. There was a lower proportion of patients classified as ASA grade III in the one-stage group (18 patients, $11.3 \%$ ) compared to the two-stage group (14 patients, $17.5 \%$ ), although overall there was no statistical difference between the ASA variations in the two groups (Table II).

The overall rate of major complications was $8.2 \%$ (13 patients) in the one-stage group but there were none in the two-stage group ( $\mathrm{p}=0.005$, rate difference $0.08,95 \%$ confidence interval (CI) 0.04 to 0.13 ) (Table III). In the 13 patients with major complications, ten $(76.9 \%)$ were due to venous thromboembolism. The single death in the one-stage group was due to pulmonary embolism. Of the patients with venous thromboembolism, four were readmitted to hospital. No evidence was found that each individual major complication by itself was significantly different between the two groups $(\mathrm{p}=0.266)$, nor that they depended on a particular surgeon $(\mathrm{p}=0.238)$ (Table IV). Statistically, there was an association between the ASA grade and individual major complications $(\mathrm{p}=0.029)$, with higher proportions noted for pulmonary embolism with an 
Table II. Comparison of patient data between the two groups

\begin{tabular}{|c|c|c|c|}
\hline & One-stage bilateral UKR ${ }^{*}$ & Two-stage bilateral UKR & p-value \\
\hline Number of patients & 159 & 80 & \\
\hline \multicolumn{4}{|l|}{ Gender (number, \%) } \\
\hline Male & $92(57.9)$ & $35(43.7)$ & $0.019^{\dagger}$ \\
\hline Female & $67(42.1)$ & $45(56.3)$ & \\
\hline \multicolumn{4}{|l|}{ Mean age in yrs (range) } \\
\hline First operation & 66.0 (42 to 85 ) & 65.0 (48 to 85$)$ & \\
\hline Second operation & $N / A^{\ddagger}$ & 66.4 (49 to 86$)$ & $0.385^{\pi}$ \\
\hline \multicolumn{4}{|l|}{$\mathrm{ASA}^{\S}$ grade (number, \%) } \\
\hline 1 & $33(20.8)$ & $18(22.5)$ & \\
\hline II & $108(67.9)$ & $48(60.0)$ & $0.34^{\dagger}$ \\
\hline III & $18(11.3)$ & $14(17.5)$ & \\
\hline IV & $0(0.0)$ & $0(0.0)$ & \\
\hline Mean duration of anaesthesia in mins (range) & 113.7 (45 to 180 ) & $\begin{array}{l}129.35 \text { (80 to } 190) \\
\text { (Sum total of both procedures) }\end{array}$ & $<0.001^{\uparrow}$ \\
\hline \multicolumn{4}{|l|}{ Mean tourniquet time in mins (range) (number) } \\
\hline Right leg & $54.7(22$ to 91$)(81)$ & $58.54(30$ to 100$)(57)$ & $0.219^{\dagger}$ \\
\hline Left leg & $54.4(24$ to 100$)(80)$ & $56.32(32$ to 90$)(65)$ & $0.404^{\dagger}$ \\
\hline \multicolumn{4}{|l|}{ * UKR, unicompartmental knee replacement } \\
\hline \multicolumn{4}{|l|}{ † Fisher's exact test } \\
\hline \multicolumn{4}{|l|}{ ‡ N/A, not available } \\
\hline \multicolumn{4}{|l|}{$\S$ ASA, American Society of Anesthesiologists } \\
\hline I Mann-Whitney U test & & & \\
\hline
\end{tabular}

ASA grade I and II, and cardiac arrhythmia with ASA grade III. None of the six one-stage simultaneous bilateral UKRs had major complications.

Of the minor complications, four patients in the onestage group developed superficial wound infection and two in the two-stage group $(\mathrm{p}=1)$. The two-stage group had three patients with a distal DVT, whereas the one-stage group had none $(\mathrm{p}=0.036)$ (Table III). A total of 13 patients $(8.2 \%)$ in the one-stage group and $11(13.8 \%)$ in the two-stage group had clinical signs of DVT, all of whom were investigated with Duplex venous ultrasound without identifying any DVTs.

The median length of hospital stay in the one-stage group at five days (2 to 19) was one day less than for the two-stage group, which had a similar range (2 to 15 ) (Table II).

\section{Discussion}

This study showed a significant difference in the rate of major complications between one- and two-stage UKR. Although the incidence of each individual major complication was small, the cumulative total was significant and has not previously been studied. In a brief communication, Boniforti and Romagnoli ${ }^{21}$ compared 40 one-stage sequential UKR with unilateral UKR and found no difference in the rate of complications. Otherwise, only two-stage bilateral UKR has been described, included within certain outcome studies. ${ }^{22,23}$ In a report on a large case series of phase III Oxford UKRs in which 502 were unilateral, ${ }^{15} 11$

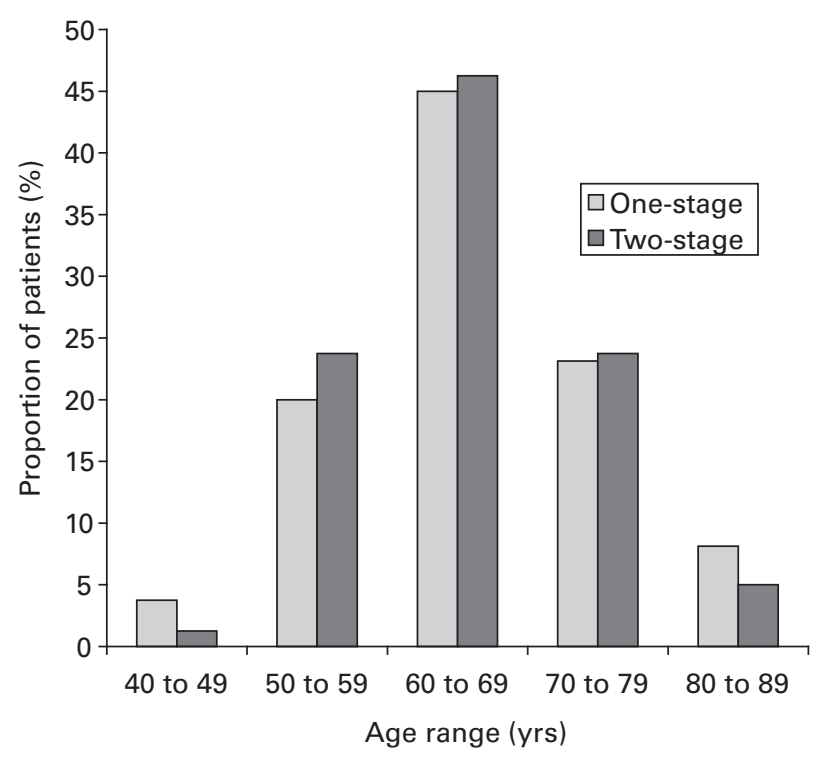

Fig. 1

Histogram to show the proportional distribution of age in the two groups.

were one-stage simultaneous bilateral and 82 were twostage bilateral procedures, one one-stage bilateral patient had a pulmonary embolus but was later found to have caecal carcinoma. The rate of complications in the bilateral 
Table III. One-stage and two-stage unicondylar knee replacement (UKR) complication rates

\begin{tabular}{|c|c|c|c|}
\hline Complications & One-stage UKR ( $n=159)(\%)$ & Two-staged UKR $(n=80)(\%)$ & p-value ${ }^{*}$ \\
\hline \multicolumn{4}{|l|}{ Major } \\
\hline Death & $1(0.6)$ & $0(0)$ & \\
\hline Pulmonary embolus & $6(3.8)$ & $0(0)$ & \\
\hline Proximal deep-vein thrombosis & $3(1.9)$ & $0(0)$ & \\
\hline Myocardial infarction & $1(0.6)$ & $0(0)$ & \\
\hline Cardiac arrhythmia & $2(1.3)$ & $0(0)$ & \\
\hline Total major complications & $13(8.2)$ & $0(0)$ & 0.005 \\
\hline \multicolumn{4}{|l|}{ Minor } \\
\hline Wound infection & $4(2.5)$ & $2(2.5)$ & 1 \\
\hline Distal deep-vein thrombosis & $0(0)$ & $3(3.8)$ & 0.036 \\
\hline
\end{tabular}

* Fisher's exact test

Table IV. Complication rates in relation to surgeon in 159 patients undergoing one-stage surgery. There was no evidence that the incidence was surgeon-specific (Fisher's exact test, $p=0.238$ )

\begin{tabular}{|c|c|c|c|}
\hline Surgeon & Number of patients for each surgeon (\%) & Number of complications for each surgeon & $\begin{array}{l}\text { Complications as a percentage of total } \\
\text { number of one-stage procedures ( } n=159)\end{array}$ \\
\hline$A$ & $91(57.2)$ & 4 & 2.5 \\
\hline B & $13(8.2)$ & 2 & 1.3 \\
\hline $\mathrm{C}$ & $20(12.6)$ & 1 & 0.6 \\
\hline D & $5(3.1)$ & 2 & 1.3 \\
\hline$E$ & $10(6.3)$ & 2 & 1.3 \\
\hline $\mathrm{F}$ & $10(6.3)$ & 1 & 0.6 \\
\hline G & $5(3.1)$ & 1 & 0.6 \\
\hline $\mathrm{H}$ & $3(1.9)$ & 0 & 0 \\
\hline I & $2(1.3)$ & 0 & 0 \\
\hline $\mathrm{J}$ & $0(0)$ & & \\
\hline
\end{tabular}

Surgeon $\mathrm{J}$ did not perform any one-stage bilateral unicondylar knee replacements

groups was not specifically assessed, and in any event the one-stage group was too small for meaningful comparisons.

In bilateral TKR, some reports express concern that a onestage procedure is associated with an increased number of complications, ${ }^{1-4,24}$ but contrasting studies means the evidence is still inconclusive. ${ }^{5-7}$ It could be argued that differences between the one-stage and two-stage groups might be due to demographic variables and surgeon throughput, with many studies citing patient age and ASA grade to be significant predictors of peri-operative complications. ${ }^{17-20,25}$ Additionally, some studies report higher mortality risks in patients with pre-existing cardiopulmonary disease., ${ }^{2,3}$ Our results were obtained from two broadly comparable groups for ASA grade and tourniquet times, and all patients had the same pre- and post-operative management. As expected, the mean anaesthetic time and median length of stay for the one-stage group was longer than for each individual operation in the two-stage group. The longer period of relative immobility might account for the increased incidence of DVT and pulmonary embolism in the single-stage group. All three patients with cardiac complications were ASA grade III, two of whom already had a history of cardiac disease. The extended anaesthetic time might have contributed to these patients' post-operative complications.
Therefore, we would advocate caution in undertaking onestage bilateral UKR in high-risk patients and those with cardiac comorbidities. Of the other patients with major complications, controlled hypertension in two of them was the only comorbidity present. None of the six simultaneous one-stage patients ( 12 knees) had any major complications, but the small number makes it difficult to draw meaningful conclusions.

Although there were significantly more patients ( $p=0.036$ ) with distal DVT in our study in the two-stage group interpretation of these results is difficult. We have only included proximal DVT as a major complication as it is an established cause of pulmonary embolism whereas whether a distal DVT is remains controversial. ${ }^{26-28}$

The overall rate of venous thromboembolism for the one-stage group was $6.3 \%$ (ten patients). One patient $(0.6 \%)$ had a fatal pulmonary embolism, which is comparable to rates in other published series of $0.3 \%$ to $0.8 \% .^{1,5,10,29,30}$ All nine patients $(5.7 \%)$ with proximal DVTs required a prolonged period of anticoagulation. No distal DVTs were recorded for the one-stage group. The overall venous thromboembolism rate in the two-stage group was $3.8 \%$ (three patients), all of which were distal DVTs. Both groups received early mobilisation and intra- 
operative mechanical calf pumps, which are recognised methods of venous thromboembolism prophylaxis. ${ }^{31,32}$ There is no evidence that the addition of chemical thromboprophylaxis would actually reduce the risk of venous thromboembolism in TKR, ${ }^{33-35}$ and in our study the rates of DVT in both groups are also comparable to those published in other series recording the incidence of DVT in unilateral knee arthroscopy. ${ }^{36,37}$

This study has a number of weaknesses. In order to exclude the possibility of selection bias and to be certain that the two groups were comparable would have required randomisation. Nor can we be certain that the pre-operative pain and function levels were the same for both groups, and that some of the two-stage patients did not have bilateral symptoms when the first operation was undertaken. Our patients were not routinely screened for venous thromboembolism post-operatively, which may increase the reported rate. ${ }^{38}$ However, pooling the results achieved from several surgeons increases the generalisability of our findings.

In our study patients who had one-stage bilateral UKRs had a significantly higher rate of major complications than those who had a two-stage procedure. We would therefore advocate caution in undertaking one-stage bilateral UKR.

\section{Supplementary material}

$\dddot{A}$ A further opinion by Mr R. Allum is available with the electronic version of this article on our website at www.jbjs.org.uk

The authors wish to thank Mrs L. Dennison for secretarial help with this study. No benefits in any form have been received or will be received from a commercial party related directly or indirectly to the subject of this article.

\section{References}

1. Bullock DP, Sporer SM, Shirreffs TG. Comparison of simultaneous bilateral with unilateral total knee arthroplasty in terms of perioperative complications. J Bone Joint Surg [Am] 2003;85-A:1981-6.

2. Leonard L, Williamson DM, Ivory JP, Jennison C. An evaluation of the safety and efficacy of simultaneous bilateral total knee arthroplasty. J Arthroplasty 2003;18:972-8.

3. Parvizi J, Sullivan TA, Trousdale RT, Lewallen DG. Thirty-day mortality after total knee arthroplasty. J Bone Joint Surg [Am]2001;83-A:1157-61.

4. Restrepo C, Parvizi J, Dietrich T, Einhorn TA. Safety of simultaneous bilatera total knee arthroplasty: a meta-analysis. J Bone Joint Surg [Am] 2007;89-A:1220-6.

5. Ritter MA, Harty LD, Davis KE, Meding JB, Berend M. Simultaneous bilateral, staged bilateral, and unilateral total knee arthroplasty: a survival analysis. J Bone Joint Surg [Am] 2003;85-A:1532-7

6. Ritter MA, Harty LD. Simultaneous bilateral knee replacements: the outcomes justify its use. Clin Orthop 2004;428:84-6.

7. Stanley D, Stockley I, Getty CJ. Simultaneous or staged bilateral total knee replacements in rheumatoid arthritis: a prospective study. J Bone Joint Surg $[\mathrm{Br}]$ 1990;72-B:772-4.

8. Macario A, Schilling P, Rubio R, Goodman S. Economics of one-stage versus two-stage bilateral total knee arthroplasties. Clin Orthop 2003;414:149-56.

9. Lorenze M, Huo MH, Zatorski LE, Keggi KJ. A comparison of the cost effectiveness of one-stage versus two-stage bilateral total hip replacement. Orthopedics 1998;21:1249-52.

10. Kim YH, Choi YW, Kim JS. Simultaneous bilateral sequential total knee replacement is as safe as unilateral total knee replacement. J Bone Joint Surg [Br] 2009;91B:64-8.
11. Svärd UC, Price AJ. Oxford medial unicompartmental knee arthroplasty: a survival analysis of an independent series. J Bone Joint Surg [Br] 2001;83-B:191-4.

12. Murray DW, Goodfellow JW, O'Connor JJ. The Oxford medial unicompartmental arthroplasty: a ten-year survival study. J Bone Joint Surg [Br] 1998;80-B:983-9.

13. Laurencin CT, Zelicof SB, Scott RD, Ewald FC. Unicompartmental versus total knee arthroplasty in the same patient: a comparative study. Clin Orthop 1991;273:151-6.

14. Rougraff BT, Heck DA, Gibson AE. A comparison of tricompartmental and unicompartmental arthroplasty for the treatment of gonarthrosis. Clin Orthop 1991;273:157-64.

15. Pandit H, Jenkins C, Barker K, Dodd CA, Murray DW. The Oxford medial unicompartmental knee replacement using a minimally-invasive approach. J Bone Joint Surg [Br] 2006;88-B:54-60.

16. No authors listed. The American Society of Anaesthesiologists. http:// www.asaha.org/clinical/physicalstatus.htm (date last accessed 18 August 2009).

17. Prause G, Ratzenhofer-Comenda B, Pierer F, et al. Can ASA grade or Goldman's cardiac risk index predict peri-operative mortality?: a study of 16227 patients. Anaesthesia 1997:52:203-6.

18. Vacanti VJ, VanHouten RJ, Hill RC. A statistical analysis of the relationship of physical status to postoperative mortality in 68,388 cases. Anesth Analg 1970;49:564-6.

19. Donati A, Ruzzi M, Adrario E, et al. A new and feasible model for predicting operative risk. Br J Anaesth 2004;93:393-9.

20. Wolters U, Wolf T, Stützer H, Schröder T. ASA classification and perioperative variables as predictors of postoperative outcome. Br J Anaesth 1996;77:217-22.

21. Boniforti F, Romagnoli S. Bilateral sequential unicompartmental knee replacement. J Bone Joint Surg [Br] 2006;88-B(Supp III):423.

22. Berger RA, Meneghini MR, Jacobs JJ, et al. Results of unicompartmental knee arthroplasty at a minimum of ten years of follow-up. J Bone Joint Surg [Am] 2005;87A:999-1006

23. Argenson JN, Chevrol-Benkeddache Y, Aubaniac JM. Modern unicompartmental knee arthroplasty with cement: a three to ten-year follow-up study. J Bone Joint Surg [Am] 2002;84-A:2235-9.

24. Hutchinson JR, Parish EN, Cross MJ. A comparison of bilateral uncemented total knee arthroplasty: simultaneous or staged? J Bone Joint Surg [Br]2006;88-B:40-3.

25. Dodds C, Murray DW. Preoperative assessment of the elderly. $\mathrm{Br} \mathrm{J}$ Anaesth 2001;1:181-4.

26. Kim YH, Kim JS. Incidence and natural history of deep-vein thrombosis after total knee arthroplasty: a prospective, randomised study. J Bone Joint Surg [Br] 2002;84B:566-70.

27. Pellegrini VD Jr, Langhans MJ, Totterman S, Marder VJ, Francis CW. Embolic complications of calf thrombosis following total hip arthroplasty. J Arthroplasty 1993;8:449-57.

28. Moser KM, LeMoine JR. Is embolic risk conditioned by location of deep venous thrombosis? Ann Intern Med 1981;94(4 Pt 1):439-44.

29. Gill GS, Mills D, Joshi AB. Mortality following primary total knee arthroplasty. J Bone Joint Surg [Am]2003;85-A:432-5.

30. Morrey BF, Adams RA, Ilstrup DM, Bryan RS. Complications and mortality associated with bilateral or unilateral total knee arthroplasty. J Bone Joint Surg [Am] 1987;69-A:484-8.

31. Unwin AJ, Jones JR, Harries WJ. Current UK opinion on thromboprophylaxis in orthopaedic surgery: its use in routine total hip and knee arthroplasty. Ann R Coll Surg Eng/ 1995;77:351-4.

32. Westrich GH, Haas SB, Mosca P, Peterson P. Meta-analysis of thromboembolic prophylaxis after total knee arthroplasty. J Bone Joint Surg [Br] 2000;82-B:795-800.

33. No authors listed. National Joint Registry for England and Wales 5th Annual Report 2008. http://www.njrcentre.org.uk (date last accessed 18 April 2009).

34. Warwick DJ, Whitehouse S. Symptomatic venous thromboembolism after total knee replacement. J Bone Joint Surg [Br] 1997;79-B:780-6.

35. Khaw FM, Moran CG, Pinder IM, Smith SR. The incidence of fatal pulmonary embolism after knee replacement with no prophylactic anticoagulation. J Bone Joint Surg [Br] 1993;75-B:940-1.

36. Ramos J, Perrotta C, Badariotti G, Berenstein G. Interventions for preventing venous thromboembolism in adults undergoing knee arthroscopy. Cochrane Database of Systematic Reviews 2008, Issue 4. Art. No.: CD005259. DOI: 10.1002/ 146551858.CD005259.pub3.

37. Ilahi 0, Reddy J, Ahmad I. Deep venous thrombosis after knee arthroscopy: a metaanalysis. Arthroscopy 2005;21:727-30.

38. Pierce CA, Haut ER, Kardooni S, et al. Surveillance bias and deep vein thrombosis in the national trauma data bank; the more we look, the more we find. J Trauma 2008;64:932-6. 